\title{
Maternal Authority Regarding Early Adolescents’ Social Technology Use
}

\author{
By: Anne C. Fletcher, Bethany L. Blair
}

Fletcher, A. C., \& Blair, B. L. (2014). Maternal authority regarding early adolescents’ social technology use. Journal of Family Issues, 35(1), 54-74. doi: 10.1177/0192513X12467753

Made available courtesy of Sage Publications:

http://www.dx.doi.org/10.1177/0192513X12467753

\begin{abstract}
***Reprinted with permission. No further reproduction is authorized without written permission from Sage Publications. This version of the document is not the version of record. Figures and/or pictures may be missing from this format of the document. ***
\end{abstract}

\begin{abstract}
:
Use of social technologies (e.g., cellular telephones, social networking sites) is highly prevalent among American adolescents, in some cases outpacing that of adults (Nielsen Company). Rapid cultural change such as that represented by technological advances comes with the potential to diminish elders' authority over youth. We analyzed qualitative interviews with 20 African American and European American mother-early adolescent dyads to consider ways in which mothers would—or would not—exert authority over adolescents' use of social technologies. Three distinct approaches emerged: abdication/loss of authority, conflicted authority, and retained authority. Mothers' use of these different approaches varied based on factors that included mothers' and adolescents' expertise regarding the technology being used, mothers' perceptions of risks associated with particular technologies, and mothers' and adolescents' beliefs and experiences with respect to social technology use.
\end{abstract}

Keywords: technology | authority | parenting | adolescents

\section{Article:}

Use of social technologies (e.g., cellular telephones, e-mail, instant messaging [IM], chat rooms) has become increasingly prevalent among contemporary American adolescents (Lenhart, Madden, \& Hitlin, 2011; Lenhart, Hitlin, \& Madden, 2005), to the extent that adolescents' use of several of these technologies has dramatically outpaced that of adults (Nielsen Company, 2008). Mead (1970) theorized that when cultures change quickly — technological advancements being one mode of cultural change-elders' authority over youth would diminish as a result of elders' increasing lack of cultural expertise. We considered whether or not recent advancements in communication technology might have the effect that Mead predicted by using qualitative interview data from early adolescents and their mothers to explore how mothers managed the swift adaption of social technology into their children's lives. Of particular interest was the manner in which mothers would—or would not—exert authority over adolescents' use of such 
technology, with authority defined in terms of how mothers actively develop and enforce rules governing adolescent access to and use of social technologies.

\section{Use of Social Technologies in Contemporary America}

Contemporary American society is increasingly characterized by exposure to and use of what have come to be termed social technologies, defined as the use of technological devices and programs for the purposes of communicating with and maintaining connections to others. Examples of social technologies include cellular telephones ("cell phones”) used for the purposes of conversation and text communication, e-mail, and social networking sites (e.g., Facebook, MySpace). A variety of statistics suggest that use of these technologies is highly prevalent among American adults and adolescents alike. For example, recent surveys show that $75 \%$ of all Americans own cell phones (Horrigan, 2008), and 52\% of American early adolescents own cell phones (Lenhart, 2009). Weisskirch (2009) reported that adolescents make and receive an average of 18 cell phone calls per day and their parents make and receive an average of 16 calls per day. Yet some types of social technologies are more heavily used by adolescents than by adults. A 2008 Nielson survey (Nielsen Company, 2008) indicated that adolescents (ages 13-17 years) send or receive substantially more texts per day than adults (58 vs. 11.9). Although e-mail has become the standard for electronic communication among adults and in workplace settings, adolescents are more likely to communicate with peers through use of social networking sites that incorporate IM and e-mail components (Lenhart et al., 2005). Heavier use of some types of social technologies among adolescents as compared with adults occurs concurrently with differences in attitudes toward such technologies. For example, adolescents are more likely than their parents to report positive feelings about the role of social technology in their lives (Macgill, 2007).

\section{Theoretical Foundation}

Cultural anthropologist Margaret Mead (1970) theorized that the speed of cultural change shapes the processes by which culture is transmitted, and by extension, shapes socialization processes. Of critical importance with respect to such processes are changes in the authority structures of elder-youth relationships. Mead suggested that there are three levels of cultural transmissionpostfigurative, cofigurative, and prefigurative-with each level characterized by differences in sources of cultural authority. Within postfigurative societies, youth learn all they need to become successful adults from their elders. Within such cultures, elders have total authority over youth and there is an emphasis on continuity - an expectation that the future will be the same as the present. Cofigurative cultural transmission occurs when the cultural past is no longer expected to perfectly predict the future. Within such societies, individuals are socialized by contemporaries as well as adults, as elders are no longer viewed as the sole providers of knowledge and wisdom. Mead hypothesized that cofigurative transmission would result in conflict between youth and elders as youth attempted to restructure authority relationships with elders to permit youth access to activities required for societal success but unfamiliar to elders. Prefigurative transmission was 
hypothesized to occur when cultural change takes place so quickly that previous generations find themselves disconnected from current societal phenomena. Within prefigurative societies, the strength of elders' authority in youths' lives diminishes dramatically as the older generation falls behind youth in practical knowledge. Despite challenges to some aspects of Mead's work (Freeman, 1983), her theoretical tenets with respect to cultural transmission are generally considered conceptually sound as well as intuitively appealing (Cote, 2000).

Perhaps the strongest force that may bring about the advent of prefigurative cultural transmission is technological development. The decades since Mead set forth her theoretical propositions have been characterized by rapid technological change such that contemporary American adolescents have regular access to technologies and technological devices that were nonexistent at the time of their parents' adolescence. These include laptop computers, cell phones, and the Internet, to name a few. Mead proposed that advancements in technology would inevitably result in cultural shifts with such shifts having implications for authority relationships. Today's adolescents are aware of the benefits, and often necessity, of social technology use and thus are highly likely to incorporate technology use into their everyday lives (Lenhart, 2010). This becomes problematic when adolescents' familiarity and proficiency with such technologies exceeds that of their parents. According to Mead, this is likely to result in challenges to parents' abilities to effectively assert authority with respect to their children's use of such technologies.

\section{Perceived Legitimacy of Parental Authority}

The premise that parental limitations, with respect to use of and understanding concerning social technologies, may interfere with their ability to guide their children's use of such technologies has not been investigated empirically. However, Smetana and colleagues (Smetana, 1988, 2000; Smetana \& Asquith, 1994) demonstrated that the effectiveness of parental authority relies in part on mothers' and adolescents' perceptions of the legitimacy of that authority. Adolescents are more likely to perceive parents' authority as appropriate in the domains of moral and conventional issues. In contrast, personal and multifaceted issues are more likely to be perceived by adolescents as under their own jurisdiction and less the appropriate domain of parental authority. Adolescent use of social technologies is likely to represent a multifaceted issue given that it incorporates components that are likely to be considered personal by adolescents (the identity and nature of social partners, organization of social networking pages) and those that are considered moral or conventional (what constitutes appropriate language for or content of communications). Parental monitoring of adolescent behavior has been demonstrated to be more prevalent when adolescents believe that their parents' authority is legitimate (Smetana, 2002), suggesting that parental exertion of authority with respect to use of social technologies may be an area of complex negotiation between parents and adolescents.

In addition, issues related to parental technological proficiency may affect the extent to which parents perceive themselves as legitimate authorities regarding their children's use of social technologies - as well as the extent to which adolescents perceive such authority as legitimate. 
Adolescents are more likely than their parents to be frequent and proficient users of specific social technologies such as texting (Nielsen Company, 2008) and social networking sites (Lenhart et al., 2005). Such discrepancies in usage patterns may result in parents feeling less confident in their ability to make and enforce rules regarding such activities. Laupa and Turiel (1993) demonstrated that when children judge the legitimacy of authority, they use their perceptions of individuals' knowledge as much as the individuals' adult status. Peterson (1986) discussed parental power as multidimensional, with one dimension related to being perceived as an expert. Parental expert power influences adolescent autonomy development in ways that are unique from other dimensions of parental power. Parents who are low in expert power with respect to use of social technology may have children who are more autonomous with respect to use of such technologies-autonomy that is accompanied by lower levels of perceived parental authority as experienced by adolescents and parents alike.

\section{Parental Authority With Respect to Adolescent Use of Social Technologies}

Despite the high prevalence in use of social technologies by contemporary American adolescents and theoretical work (Mead, 1970) suggesting that supervision and limit-setting with respect to such use may represent a parenting challenge, there has been little empirical work considering the manner in which parents may or may not exert authority in this area of their children's lives. Work that has been conducted in this area (Sook-Jung \& Young-Gil, 2007;Tripp, 2011) has focused primarily on parents' efforts to monitor and restrict adolescent use of the Internet (including access to specific websites).

Work focusing on parental monitoring and restriction of Internet use suggests that such efforts are infrequent (although more frequent for younger adolescents) and largely ineffective. Dehue, Bolman, and Völlink (2008) found that although parents reported setting rules concerning their children's use of the Internet, monitoring of Internet use was sufficiently infrequent that parents were rarely aware that children had experienced cyberbullying. Sook-Jung and Young-Gil (2007) administered surveys to fourth-, fifth-, and sixth-grade children in Korea and found that parental restrictions with respect to time spent on the Internet and websites that children were permitted to access were unassociated with reported Internet usage. Wang, Bianchi, and Raley (2005) found that although 66\% of parents of adolescents reported having family rules about adolescents’ Internet use, only 38\% of adolescents reported having family rules regarding Internet use. Rates of monitoring within this sample were higher with younger adolescents.

In a particularly informative investigation of parental efforts to exert authority over ("mediate”) adolescents’ Internet use, Eastin, Greenberg, and Hofschire (2006) conducted telephone surveys of mothers of adolescents to determine the types of mediation used with respect to Internet use, as well as whether mediation efforts were associated with parenting style. Mothers reported using a variety of mediation strategies including provision/nonprovision of Internet access (defined in terms of whether the Internet was available to adolescents in their homes and in their bedrooms), interpretive mediation (discussing online content with adolescents), coviewing 
mediation, restrictive mediation (time and content restrictions), and technological mediation (use of parental control software). Rates of virtually all mediation activities varied across parenting style groups, with authoritative parents the most likely to engage in mediation, followed by authoritarian parents.

In another study focusing on parents' attempts to exert authority over adolescents' use of a social technology, Rosen, Cheever, and Carrier (2008)administered surveys to adolescents and their parents concerning perceptions of online dangers and parents' attempts to set limits on MySpace use. Results indicated that parents perceived considerable potential dangers associated with use of the Internet and MySpace, yet levels of concern were not reflected in parental efforts to limit or monitor use of this technology. Parental efforts at limiting and monitoring were especially low with older adolescents.

\section{The Current Study}

Use of social technologies represents a highly salient and prevalent aspect of adolescent life within contemporary American society. The theoretical perspective elaborated by Mead with respect to patterns of cultural transmission suggests that use of such technologies may represent a challenge to parents who are less likely to be proficient and comfortable with their use.

Specifically, parents may find it difficult to monitor and restrict adolescents' use of technologies with which they are less familiar. We explore these issues through analysis of qualitative interview data collected from early adolescents and their mothers focusing on the manner in which adolescents and mothers have kept pace with rapidly evolving social technologies, as well as the implications of attitudes and capabilities with respect to social technologies for maternal efforts to manage adolescents' use of these technologies.

\section{Method}

\section{Participants}

The current study drew participants from a larger, mixed methods longitudinal study of maternal involvement in children's friendships. Participants in the current study were a subset of 20 mother-child dyads (10 boys and their mothers and 10 girls and their mothers; 10 European American dyads and 10 African American) drawn from this larger study who participated in qualitative interviews during children's seventh-grade year. One mother was not included in the current study because of incomplete interview data, but the child within this dyad was retained.

The qualitative sample represented a range of social classes and family structures. Hollingshead (1975) classifications were used to assess family social class, and three families were classified as upper class, eight upper middle class, six middle class, and three lower class. Thirteen adolescents resided with their biological mothers and fathers, three with single mothers, and four with their mothers and another adult (e.g., a stepfather, mother's boyfriend, or grandmother). All participants were given pseudonyms for the purposes of this article. 


\section{Procedure}

Interviews took place in families' homes with a matched-ethnicity graduate research assistant and an undergraduate research assistant. Interviews were conducted with mothers and adolescents separately. All participants were asked a series of questions related to adolescents' use of social technologies and mothers' and adolescents' beliefs and behaviors regarding such use. Specifically, questions focused on (a) what types of social technology adolescents used, how often, with whom, and when/where; (b) the ways in which mothers monitored adolescents' social technology use; (c) rules mothers established regarding adolescents' social technology use; and (d) perceptions of various types of social technology, including the risks and benefits ascribed to specific technologies.

\section{Data Analysis}

An axial coding strategy was implemented such that we began with repeated readings of all 39 interviews, for the purpose of gaining a broad sense of how early adolescents and their mothers talked about and perceived adolescents' use of social technologies. Throughout these readings, the two authors met regularly and discussed impressions of the data and emerging themes. We then began developing codes that focused on the manner in which mothers exerted authority over early adolescents' use of various technologies. These codes were refined and additional codes added through an iterative process that involved multiple readings of transcripts by both authors and discussions regarding transcript and code content. Over the course of this process, codes emerged that focused on maternal proficiency with and value for social technologies and the various manners in which mothers did or did not demonstrate authority over adolescents' use of such technologies.

When a comprehensive list of codes was agreed on, each author independently applied it to a subsample of the transcripts. During independent coding, the authors wrote memos noting any problems encountered as well as thoughts regarding the utility of each code. After initial coding was completed, all coding decisions and memos were compared and discussed. Through this process, potential problems with the coding scheme were discovered and addressed. Following independent coding of the full set of transcripts, comparisons across coders (authors) revealed a high degree of reliability. All discrepancies were discussed and resolved through consensus.

Atlas.ti software was used to manage data and was also used in the next step of analysis: data organization. Data were grouped by code and then grouped codes were examined for patterns. Finally, using a cross-case analysis approach (case-oriented and variable-oriented), grouped sections of code were analyzed to capture emerging themes as they related to parent and child reflections regarding early adolescents' use of social technologies (Miles \& Huberman, 1994) and transcripts were reviewed a final time with simultaneous memoing with respect to the intersection of various authority patterns with characteristics of children, mothers, and technologies that might explain variation. 


\section{Results}

\section{Adolescent Versus Maternal Technological Knowledge, Interest, and Beliefs}

Participants used multiple forms of social technology including cell phones, e-mail, and IM.

Early adolescents were more actively engaged with these technologies than mothers and tended to use more diverse types of technologies than mothers. Most mothers used cell phones and email at least occasionally. Early adolescents used cell phones and e-mail as well, but were also likely to use IM, social networking sites, online video games with communication components, and texting.

\section{Technological Knowledge and Proficiency}

In general, mothers demonstrated a lack of knowledge of the most basic elements of social technology. One of the primary sources of confusion was regarding distinctions among various types of social technologies. Many mothers expressed confusion about differences among IM, chat rooms, and e-mail; however, some mothers were more aware of their lack of knowledge than others. Larina (African American mother) repeatedly mixed up chat rooms and IM as she spoke, seemingly unaware of her confusion. On the other hand, when Jackie (European American mother) was asked whether her daughter used e-mail, she responded: "I think she does. [pause] Yeah, she does. Uh, you know, I get that so confused with instant messaging and the e-mail.” Typical of many mothers in this sample, Jackie knew just enough to know that her knowledge was insufficient.

A few mothers expressed clear recognition of their lack of proficiency with social technology. These mothers understood that they were out-of-step with current technological trends. Some mothers expressed their awareness of their ignorance through self-deprecating remarks regarding their abilities: “I just do the e-mail. I'm getting to be a dinosaur” (Jane, European American mother). Other mothers commented on their situations and concerns that stemmed from their lack of ability:It's just amazing what they can do on the computer, they're so much better than me. ... [When he uses the computer for school], he will take over and do it on his own 'cause he's better at it than me. (Nancy, European American mother)

Even adolescents who were not technologically inclined demonstrated greater exposure to and understanding of social technologies than their mothers. Toby (European American boy) began his interview by saying, "I can save you a whole lot of time. I don't do any of that e-mail, instant message, or any of that.” And yet Toby was able to accurately describe and compare a wide range of social technologies, demonstrating a high level of knowledge, if not interest. In contrast, his mother Patty indicated a lack of understanding as to what such technologies were and how they were used, "I'm too ignorant to answer that right now."

\section{Concerns Regarding Social Technology Use}


Every mother in the study expressed some level of concern or doubt about adolescent use of social technologies. Sources of concern varied based on the type of technology. Regarding cell phones, mothers were generally concerned about the cost and the potential for irresponsible use: "She might end up running her mouth with it or maybe go over her minutes or something" (Natasha, African American mother). Regarding Internet use, mothers were likely to express concerns regarding adolescents accessing inappropriate websites and potential contact with online predators. This second concern was especially true for mothers of girls: "The internet is world wide, wooorld wiiide. And there are predators out there that just would just love to get a hold of her. And she has to be aware of that and keep herself safe” (Chantelle, African American mother).

In contrast, very few early adolescents expressed concerns regarding use of social technology. When concerns were mentioned, they were framed in terms of recognition of and respect for parental concerns. For example, when Chantelle’s daughter, Lateisha, discussed her mother's fears regarding predators, she stated, "I really took that to heart."

\section{Value for Social Technology}

In addition to explicit concerns regarding adolescent use of technology, some mothers expressed beliefs that there were few benefits associated with such use. Regarding the idea of early adolescents owning cell phones, Tamika (African American mother) stated, “They ain't nothing important they doing that can't wait.” Chantelle (African American mother) felt that e-mail was unnecessary for her daughter: “If you're asking me if there's a benefit, no. [laughs] There's no benefit, no.” Most mothers who devalued technology use by their children were also mothers who had low levels of knowledge or skill with respect to use of such technology. In contrast, nearly all the adolescents themselves expressed a high value for their own use of technology. In addition, mothers recognized that their adolescents perceived value where they themselves did not.

\section{Three Approaches to Maternal Technological Authority}

Most mothers expressed some awareness that social technology use required parental monitoring as well as rules and guidelines for use, but few mothers demonstrated systematic approaches to managing this task. Mothers demonstrated three primary approaches with respect to technological authority: loss or abdication of authority to others, conflicted authority, and retained authority. These approaches were not mutually exclusive; mothers demonstrated different types of approaches under varying circumstances and with respect to different technologies. Yet overall, mothers' preferences for these approaches were linked with their own levels of technological knowledge and concerns regarding adolescents' use of social technologies.

\section{Abdication/Loss of Authority}


In some cases, mothers lost or abdicated their technological authority, allowing other individuals or institutions to determine the manner in which adolescents could use social technologies. Although all the mothers in the sample had occasions or circumstances under which they lost or abdicated technological authority, mothers with higher levels of technological knowledge tended to be less likely to experience such loss. Mothers’ and adolescents’ discussions of lost or abdicated authority indicated that technological authority was sometimes absent because mothers were unable to take authority or had not considered that authority was needed - thus placing authority in the hands of the child. In other circumstances, authority was explicitly abdicated to other sources, such as the child's father or parental control software.

\section{Loss to the child's father}

At times, mothers did not actively demonstrate technological authority because they considered the child's father as the authority with respect to technology. Most mothers who took this approach seemed uncomfortable with it. They giggled and faltered in their speech as they described their own lack of involvement in supervising their children's use of social technologies and assumptions that children's fathers would serve as authorities in this arena: "I don't, well, [pause] my husband's more in charge of that. [laughs] He says he watches what [our son] does” (Sarah, African American mother). When asked about her thoughts on her son using e-mail, Ophelia (African American mother) responded, "His father be on it more than I do, so [laughs] I'm not on it that much.”

\section{Loss to parental control software}

There are many software and setting options available for parents wishing to limit children's access to certain social technologies. For a number of mothers, filters and restrictions were viewed as an alternative to active maternal supervision of adolescents' social technology use: “I have things set on my computers so that rules like that aren't an issue . . . I have the parenting control software, mm-hm” (Jill, European American mother). Nate, an African American boy, was asked about rules his parents had for his social technology use and responded, "They like the firewall and all this stuff, and so they don't have to [set rules].” Just as Nate demonstrated confusion between parental control software and firewalls, which are a type of virus protection and have no utility for monitoring internet use, mothers also demonstrated confusion about such software. Most mothers who used parental controls did not seem to fully understand the software. Their discussions of controls demonstrated confusion over the ways parental control software worked as well as the settings they personally had selected on the software: "Think he was restricted from gettin’ incoming e-mails, I think I restricted him . . . I think I had it so outgoing stuff couldn't come in, maybe,” Tamika (African American mother) reported. Mothers

such as Tamika abdicated authority to parental control software when they did not understand or they ignored the role of parents in making sure software worked effectively. Mothers with low levels of technological knowledge were particularly likely to delegate technological authority to parental control software. 


\section{Loss to the child}

Many early adolescents were given considerable freedom in their use of social technologies because mothers believed that they did not need supervision. Some participants, such as Steven's (African American boy) mother, explicitly left it to their children to maintain authority over their own social technology use: "She just tells me it's my responsibility." Some mothers expressed beliefs that their children would not or had not yet used social technology inappropriately and thus they trusted their children to monitor themselves: “We don’t really have any [rules], 'cause I mean they know I'm not gonna be doing anything on there” (Toby, European American boy). Carol (African American mother) did not have concerns about her daughter's cell phone use because "I have never walked in on her having a conversation that I thought was inappropriate for her to be having, so she does pretty good." Other mothers delegated technological authority to their adolescents more implicitly, such as when they allowed their children to have computers in their own bedrooms, thereby limiting the control mothers could have over social technology use. Mothers who expressed high levels of trust in their children's abilities to use social technologies responsibly were less likely to maintain authority with respect to such use.

\section{Conflicted Authority}

Mothers sometimes found themselves in circumstances in which their technological authority was conflicted or unclear. In such cases, authority was divided between mothers and other key individuals (e.g., children themselves) or institutions (e.g., schools). Such divisions were sometimes emotionally charged and almost always represented areas of active negotiation within the mother-adolescent relationship.

\section{Conflicted authority: Mothers and adolescents}

Most cases of conflicted technological authority involving adolescents were the result of mothers' reluctance or inability to adequately take charge of their adolescents' social technology use. This was especially clear in the expression of rules mothers set regarding adolescents' technology use. In some cases, rules were unclear or nonspecific. Laura, an African American mother, discussed the rules she had for her daughter's cell phone use: "Only on the weekends, and, uh, just on the weekends, I prefer.” When asked if her daughter ever used her cell phone on school nights, Laura responded, “Um, maybe sometimes.” In other cases, mothers had expectations for their adolescents' technology use that had not been communicated to adolescents. Cathy (African American mother) explained it this way: "I don't use chat rooms so I wouldn't want them to use chat rooms.” However, Cathy’s daughter, Keisha, was not aware that avoiding chat rooms was a rule in her family.

Conflicted authority was also observed when mothers' rules regarding adolescent use of social technologies were not specific to the use of such technologies. In such cases, mothers described long-standing family rules that applied to a range of situations and did not reflect explicit authority over early adolescents’ social technology use. For example, many mothers had rules 
about not talking to strangers: “Just don’t talk to strangers, don’t tell 'em where you live and stuff like that” (Dimere, African American boy). "I'm not supposed to talk to anyone I don't know basically" (Niobe, African American girl). There were also rules about time limits that had more to do with bedtimes and homework or chores than with social technology use per se: "After 9:30 or 10 o'clock they're not supposed to be on the computer or the phone at all” (Amber, European American mother).

When she comes home from school she can generally talk as much as she wants to when she comes home from school as long as she does her homework and half-way does, she's gonna halfway do her housework, but as long as she gets done what she needs to she can talk on the [cell] phone. (Carol, African American mother)

\section{Conflicted authority: Mothers and schools}

As an additional source of authority in early adolescents' lives, schools also represented a source of conflict for mothers who wished to set rules with respect to their children's use of social technologies. Such conflict took two forms: mothers' lack of awareness concerning schools' policies and practices regarding social technology use and overt disagreement with school policies and practices.

Both mothers and adolescents expressed consistent confusion regarding school policies regarding social technology use. For example, very few participants were entirely certain whether cell phones were allowed at school. Confusion was expressed in comments, including, "I guess you can bring it as long as it's turned off. Not on the volume low or anything, off” (Ashley, European American girl) or "I think they don't want our phones there, but it's not a problem if they were to see it as long you're not on it, and, um, it's not ringing and stuff, and not using it” (Lateisha, African American girl). Mothers were also often ignorant of school practices with respect to student Internet use. When asked about her daughter's access to e-mail, Jessica (African American mother) responded, "Not unless she, she uses at school, but I'm quite sure they don't have that at school. They're not supposed to.” Laura (African American mother) was even less clear about her daughter's use of e-mail at school:I think they did at school, cause they tell me they was setting up an account. ... And then they told me, we got to get rid of it because, um, it was the one where they was sending out, um, people, predators was on that, and they were targeting the children.

Confusion regarding technology-focused school policies and practices was especially prevalent among mothers with low levels of technological knowledge.

Adding to mothers' confusion regarding school policies were changes in such policies. Hillary (African American girl) described a change in school policy that would now allow students to take their cell phones to school as long as the phones were not used during school hours "because there might be something like an activity be cancelled and we can't use all the [school] phone at once.” As she was talking about this issue, her father walked by and Hillary called to 
him: "So you might have to start thinking about that. Can I start taking it to school?" This exchange illustrated the manner in which conflicted authority involving parents and schools unfolds against a backdrop of changing rules and regulations that can result in parents not even knowing that a conflict exists.

In a few cases, mothers were aware of school policies, but actively disagreed with these policies. Mothers were particularly likely to disagree with, and encourage their children to violate, rules prohibiting cell phones at school. Scott's mother used his cell phone daily as a means of communicating with him while she was at work, despite policies prohibiting cell phone use at school and on the school bus:[My parents] leave me voice-mails like when I'm at school and they need to tell me something. That way I can check it on the bus. 'Cause usually you're not supposed to have them on the bus, but my bus driver really don't care.

Mothers felt that their parenting abilities and children's safety were potentially compromised by school policies prohibiting cell phones. As Jackie (European American mother) stated, "You know, you hear about all these things happening at school, and they're not supposed to have [cell phones] at school, but if there was ever an emergency, I would know that she had it.”

\section{Authority Retained}

Despite mothers' limitations with respect to knowledge about and interest in social technology, many mothers did find ways to retain their parental authority with respect to adolescent technology use. Maternal authority was expressed in terms of both setting and enforcing rules specific to adolescents' use of social technologies and active monitoring of such use.

\section{Setting and enforcing rules}

The most common way that mothers retained their technological authority was by setting clear, relevant rules for the use of social technologies and then enforcing these rules. Many of these rules simply forbid adolescents from using certain types of social technologies: "My mama only let us use [the computer] for homework" (China, African American girl). Not allowing adolescents to use certain types of social technologies was a rule type generally observed when mothers had lower levels of understanding concerning how a technology of interest worked and were also clearly aware of the limitations of their own understanding. For instance, Patty (European American mother) described the reason her son was not allowed to use e-mail: "Part of it I guess is just that I haven't really had the time to deal with it. [laughs] You know, to really find out about how it all works and what the ramifications would be.” Amber (European American mother) was quite knowledgeable about most social technologies and yet was still fearful that she did not know enough about MySpace to allow her daughter to use it:When something popped up on my screen I found out that she did have a page on MySpace ... And she told me that it was secure, but I made her close the account. I said, I don't care how secure you think it is. 
When Scott joined a Star Wars chat group, his mother discovered it and immediately had him unsubscribe: “[My parents] just didn’t want me talking to other people.”

Other mothers had specific rules that allowed their adolescent children to use social technologies, but with limits. Toby (European American boy) described his mother's rules for his Internet use: “Don’t go on to dirty websites or get a virus on our computer." This was echoed by Ashley (European American girl), “[My parents] don’t want me to go into any nasty websites.” Almost universally, mothers had rules against going into chat rooms; in fact, this was the only rule for a number of mothers. "No chat rooms" (Laura, African American mother). "The rule is, she is not to go into any chat rooms,” said Amber (European American mother).

Mothers were more likely to set rules regarding and to monitor social technology use when the technology of interest was one they understood and used themselves (cell phones, e-mail). Mothers were also more likely to clearly articulate and communicate rules regarding their children's social technology use when the rules related to areas of special concern or fears on the part of mothers (chat rooms, contact with strangers).

\section{Active monitoring}

The other way that mothers retained authority was through monitoring their adolescents' social technology use. As Jackie (European American mother) stated, "I do monitor [MySpace]. And I do make [my children] pull it up or, you know, I actually have all their passwords now.” Mothers who were knowledgeable regarding social technology were able to put that knowledge to use as they monitored their early adolescents' social technology use. "I have to be able to walk in there and read [the computer screen], and if I feel the need to . . . I occasionally go on there and check the history," explained Jackie (European American mother). Scott (European American boy) described his parents' supervision of his e-mail activity: "I mean they just look at the subject and what it is and stuff." Carol (African American mother) had a clear understanding of how IM worked that allowed her to effectively monitor her child's use of this technology: "With their instant messaging, you can actually see what they're really talking about. You can see their side of the conversation and your side of the conversation.” Hillary (African American girl) explained how her mother monitored her cell phone use: "When she gets the bill, she sees who I'm

calling." Carol (African American mother) had a similar strategy according to her daughter: "She looked through my contacts and looked who called me.”

Retaining authority was most commonly observed among mothers who were knowledgeable about and had favorable attitudes toward social technologies, as well as by mothers whose adolescents were particularly active social technology users. In addition, retained authority was sometimes linked with mothers having had problems with older siblings using these same social technologies. Carol (African American mother) explained that the family computer was located in the living room so that she could monitor its use because I had more problems out with my sons on the computer than I did, I never had any with Carollee but I had them with my sons. 
'Cause they like 16 and 18 and I had to get on them because . . my home-page had got hijacked because they had went to a website and then they end up hijacking me. I like, like nnnn, ya'll can't don't touch it. And they were downloading music . . . from certain sites . . . connected to porn. And so my sons were downloading music and it was going to the porn sites.

Mothers whose lack of authority with respect to technology use had led to difficulties with older siblings were quick to discuss these problems and reflect on how such difficulties had informed the establishment of rules and monitoring of technology use with target adolescents.

\section{Discussion}

Within our sample, use of social technologies was more prevalent among early adolescents than among their mothers. Mothers were aware of their children's frequent use and high levels of proficiency with respect to these technologies, and uniformly expressed concerns regarding the manner in which their children used them. Yet even in the presence of these concerns, mothers struggled to successfully exert authority over their children's use of social technologies. Most mothers recognized their own limitations in terms of understanding how social technologies operated and the strategies — or nonstrategies — they used to maintain authority over their children's use of these technologies reflected these limitations.

Although all mothers within our sample recognized the potential for problems related to adolescents' use of social technologies, there was considerable variability in both mothers' responses to this recognition and the effectiveness of their efforts. In addition, individual mothers' efforts to monitor and restrict adolescent use of social technologies differed across different technologies. This variability was related to two factors: mothers' varying levels of technological expertise and mothers' and adolescents' beliefs and experiences with respect to social technology use.

A basic level of technological expertise regarding how specific social technologies work appears to be a prerequisite for mothers' ability to effectively monitor and control adolescents' use of such technologies. Mothers in our sample who did not understand differences between various social technologies and specifics concerning how such technologies operated were more likely to relinquish their authority over adolescents' use of such technologies and to be perceived by adolescents as incapable of monitoring technology use. This finding is consistent with work suggesting that expert knowledge represents a key component that children consider when judging the legitimacy of parental authority within a specific domain (Laupa \& Turiel, 1993; Peterson, 1986). This expert knowledge is clearly technology-specific, with mothers demonstrating greater understanding of technologies that they themselves used (e.g., cell phones; Nielsen Company, 2008) as opposed to those with which they did not have personal experience (e.g., social networking sites; Lenhart et al., 2005). Interestingly, adolescents did not express the belief that parents did not have the right to exert authority over their use of social technologies, as would be suggested by the work of Smetana and colleagues (Smetana, 
1988, 2000; Smetana \& Asquith, 1994). Rather, many adolescents and mothers alike perceived that mothers did not have the skills necessary to exert authority, even if they were presumed to have the right to do so.

Mothers' abilities to maintain authority over adolescents' use of social technologies also reflected their own and their children's experiences with such technologies. Mothers were more likely to be reactive than proactive in their efforts to monitor and restrict adolescent social technology use. When mothers were not aware of adolescents having misused social technologies, they were more likely to abdicate authority to adolescents, citing trust in adolescents as a reason why rules and monitoring were not needed. Yet when mothers had experiences with a child - specifically, an older sibling - misusing technologies, they established clear, relevant rules for adolescents' use of technology and monitored such use carefully. Mothers also were particularly likely to establish and clearly articulate rules related to one specific aspect of social technology they perceived as highly dangerous - adolescent use of chat rooms. Perceptions regarding the potential dangers of chat rooms were not necessarily related to adolescents’ or siblings’ experiences, but rather to mothers' beliefs shaped by information accessed through schools, media, and discussions with other parents. In fact, the large number of mothers who demonstrated a lack of clarity about the difference between chat rooms, IM, and social networking sites suggests that many mothers were restricting their adolescents' access to chat rooms without a clear understanding of the nature of chat rooms.

Mothers' struggles in seeking to maintain authority over adolescents' use of social technologies documented in this project are consistent with those predicted by Mead (1970) within societies characterized by rapid cultural change. With respect to use of rapidly evolving social technologies, contemporary American society in many ways illustrates what Mead termed prefigurative cultural transmission patterns, hypothesized to occur when cultural change occurs so quickly that older generations find themselves disconnected from current societal phenomena. Clearly, adolescents who participated in interviews for the current project were expert users of social technologies that did not even exist when their parents were adolescents. In addition, social technologies are evolving at such a rapid rate that even parents who have an operational understanding of social technologies their adolescents are using today (texting, social networking sites) may find that knowledge dated with a speed that challenges parenting abilities. Consistent with the predictions of Mead, the strength of elders' authority in youths' lives diminishes dramatically as the older generations fall behind youth in terms of practical knowledge and awareness concerning social technology usage.

The current effort represents one of the first to consider ways in which mothers negotiate authority issues with respect to adolescent use of technologies that mothers themselves may not use or fully understand. Our sample of 20 mother-adolescent dyads, although not unusual for qualitative inquiry, was relatively small and findings should not be generalized beyond the population of African American and European American early adolescents and their mothers residing in the southeastern portion of the United States. Yet the information yielded from this 
inquiry sheds light on a fascinating phenomenon unfolding within contemporary American culture.

Given the speed with which technology is advancing and making its way into our daily lives, it is critical that we further examine the ways in which it shapes adolescents' relationships and social interactions. The current findings demonstrate that mothers' lack of knowledge and confidence regarding technology compromises their parental authority. Future research should consider other ways in which the reversal of "expert authority" can affect parent-adolescent relationships. For example, perhaps the tension resulting from conflicted or abdicated authority can lead to changes in the quality of parent-adolescent relationships or lead to conflicted authority regarding issues unrelated to technology. The potential for parent education to alter this dynamic should also be explored. According to Mead's theory, parents may experience a loss of authority in a rapidly changing world. Our own findings are consistent with this premise. This suggests that educating parents about the technologies their adolescents are using has the potential to shift authority back to parents. This possibility suggests that the next step in this line of inquiry may be to explore ways in which such education might occur, as well as its impact on parentadolescent authority relationships.

\section{Article Notes}

- Declaration of Conflicting Interests The author(s) declared no potential conflicts of interest with respect to the research, authorship, and/or publication of this article.

- Funding The author(s) disclosed receipt of the following financial support for the research, authorship, and/or publication of this article:

This research was supported by a grant to the first author by the William T. Grant Foundation.

\section{References}

Cote J. E. (2000). The Mead-Freeman controversy in review. Journal of Youth and Adolescence, 29, 525-539.

Dehue F., Bolman C., Völlink T. (2008). Cyberbullying: Youngsters' experiences and parental perception. CyberPsychology \& Behavior, 11, 217-223.

Eastin M., Greenberg B., Hofschire L. (2006). Parenting the Internet. Journal of Communication, 56, 486-504.

Freeman D.(1983). Margaret Mead and Samoa: The making and unmaking of an anthropological myth. Cambridge, MA: Harvard University Press.

Hollingshead A. (1975). Four factor index of social status. Unpublished manuscript, Department of Sociology, Yale University, New Haven, CT. 
Horrigan J. A.(2008, March 5). Mobile access to data and information. Retrieved from http://www.pewinternet.org/Reports/2008/Mobile-Access-to-Data-andInformation.aspx

Laupa M., Turiel E. (1993). Children's concepts of authority and social contexts. Journal of Educational Psychology, 85, 191-197.

Lenhart A. (2009, August 19). Teens and mobile phones over the past five years. Retrieved from http://www.pewinternet.org/Reports/2009/14--Teens-and-Mobile-Phones-DataMemo.aspx

Lenhart A.(2010, June 10). "How do [they] even do that?” A Pew Internet guide to teens, young adults, mobile phones and social media. Retrieved fromhttp://www.pewinternet.org/Presentations/2010/Jun/How-do-they-even-do-that-APew-Internet-guide-to-teens-cell-phones-and-social-media.aspx

Lenhart A., Hitlin P., Madden M. (2005, July 27). Teens and technology. Retrieved from http://www.pewinternet.org/Reports/2005/Teens-and-Technology.aspx

Lenhart A., Madden M., Smith A., Purcell K., Zickuhr K., Rainie L. (2011, November 9). Cruelt $y$ on social network sites: How American teens navigate the new world of "digital citizenship.” Retrieved from http://pewinternet.org/Reports/2011/Teens-and-socialmedia.aspx

Macgill A. (2007, October 24). Parent and teen Internet use. Retrieved from http://www.pewinternet.org/Reports/2007/Parent-and-Teen-Internet-Use.aspx Mead M. (1970). Culture and commitment: A study of the generation gap. Garden City, NY: Natural History Press.

Miles M. B., Huberman A. M. (1994). Qualitative data analysis. Thousand Oaks, CA: Sage.

Nielsen Company. (2008, September 22). In U.S., SMS messaging tops mobile phone calling. Retrieved from http://blog.nielsen.com/nielsenwire/online_mobile/in-us-text-messaging-topsmobile-phone-calling/

Peterson G. W. (1986). Parent-youth power dimensions and the behavioral autonomy of adolescents. Journal of Adolescent Research, 1, 231-249.

Rosen L., Cheever N., Carrier L. (2008). The association of parenting style and child age with parental limit setting and adolescent MySpace behavior.Journal of Applied Developmental Psychology, 29, 459-471. doi:10.1016/j.appdev.2008.07.005

Smetana J. G. (1988). Adolescents' and parents' conceptions of parental authority. Child Development, 59, 321-335. 
Smetana J. G. (2000). Middle-class African American adolescents' and parents' conceptions of parental authority and parenting practices: A longitudinal investigation. Child Development, 71, 1672-1686.

Smetana J. G. (2002). Culture, autonomy, and personal jurisdiction in adolescent-parent relationships. In Kail R. V., Reese H. W. (Eds.), Advances in child development and behavior (Vol. 29., pp. 51-87). San Diego, CA: Academic Press.

Smetana J. G., Asquith P. (1994). Adolescents' and parents' conceptions of parental authority and personal autonomy. Child Development, 65, 1147-1162.

Sook-Jung L., Young-Gil C. (2007). Children's Internet use in a family context: Influence on family relationships and parental mediation.CyberPsychology \& Behavior, 10, 640-644.

Tripp L. M. (2011). "The computer is not for you to be looking around, it is for schoolwork": Challenges for digital inclusion as Latino immigrant families negotiate children's access to the Internet. New Media \& Society, 13, 552-567. doi:10.1177/1461444810375293

Wang R., Bianchi S. M., Raley S. B. (2005). Teenagers' Internet use and family rules: A research note. Journal of Marriage and Family, 67, 1249-1258.

Weisskirch R. S. (2009). Parenting by cell phone: Parental monitoring of adolescents and family relations. Journal of Youth and Adolescence, 38, 1123-1139. doi:10.1007/s10964-008-9374-8 